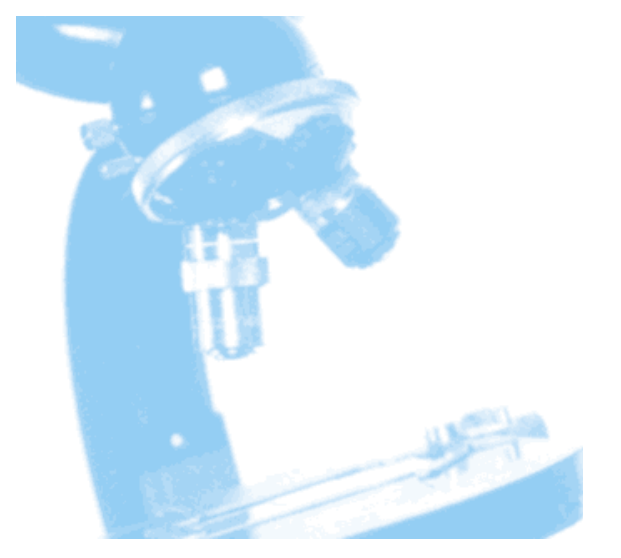

Talking about sex and sexuality is difficult for most patients and physicians. But for the $10 \%$ of the population who identify themselves as lesbian, gay, bisexual, or transgender, ${ }^{1,2}$ discussing sex can be even more confusing and uncomfortable. Many patients are unwilling to disclose their sexual orientation for fear of retaliation and discrimination. Unfortunately, the biases and prejudices of society are not always left at the door to the examination room and may affect the quality of health care received by patients who are lesbian, gay, bisexual, or transgender.

Health care professionals often assume that their patients are heterosexual, which can create unease in the patient-physician relationship. The assumption of heterosexuality, or heterosexism, not only makes patients feel uncomfortable, but can also lead a physician to neglect certain aspects of health care and to provide inappropriate counseling. Some physicians are openly hostile, destroying patient trust and breaching patient confidentiality.

I present a hypothetical case of Kate, a 23-year-old female graduate student, on her first visit to a health clinic. For the purposes of this article, I will focus on the sexual history, providing examples of improper ques-

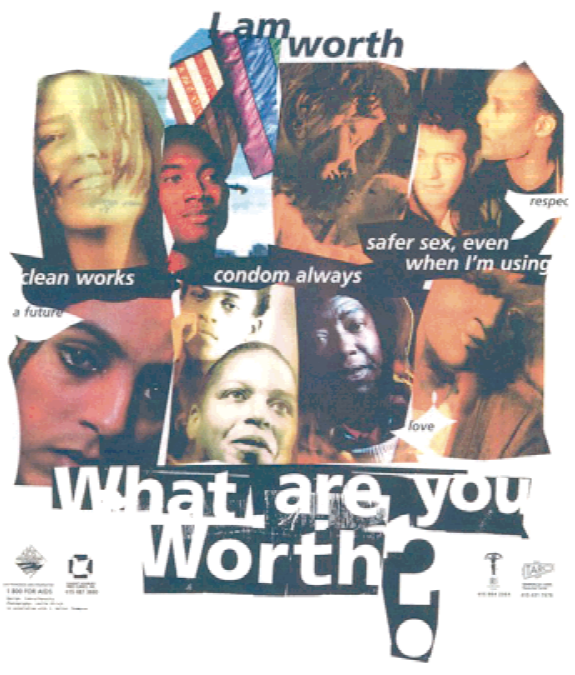

\title{
How to talk about sex with patients who are not heterosexual easo nato
}

Rita Lee, Cleveland Clinic, 9500 Euclid Ave, Mailcode NA-21, Cleveland, OH 44195

Correspondence to: ritalee69@hotmail.com

West J Med 2000;172:401-402

tions and suggestions of alternative ways of obtaining an appropriate sexual history.

\section{NEED TO ASK YOU SOME QUESTIONS THAT I ASK OF EVERY PATIENT ON THEIR FIRST VISIT TO THE CLINIC. ARE YOU SEXUALLY ACTIVE?}

Although this is a good start, patients should be reassured that the conversation is confidential before they are asked to disclose their sexual history. For many lesbian, gay, bisexual, and transgender patients, the fear of insurance, professional, and social repercussions prevents them from being open about their sexuality. Confidentiality is especially important to adolescents, who risk being ostracized from their families and peers if their sexual orientation should become known.

\section{Health care professionals}

\section{often assume that their}

\section{patients are heterosexual}

\section{WHAT FORM OF BIRTH CONTROL ARE YOU USING?}

By questioning Kate about birth control, the physician is assuming she is in a heterosexual relationship. When she replies that she does not use birth control, she receives a stern warning on the risks of pregnancy and sexually transmitted diseases. An alternative line of questioning is more useful: "Are you sexually active with men, women, or both? What forms of protection and/or contraception do you use?"

\section{HOW MANY MEN HAVE YOU HAD SEXUAL RELATIONSHIPS WITH?}

A thorough sexual history is important to provide adequate patient care and counseling.



$10 \%$ of patients are not heterosexual

However, asking Kate specifically about her past relationships with men will again make her uncomfortable and neglect her past relationships with women. Patients will often answer only the question asked. Therefore, unless open questions are asked, vital parts of a patient's history will be missed. In this case, gender-neutral terms should be used: "How many people have you had sexual relationships with? How many were with men? How many with women?"

\section{PEOPLE PARTICIPATE IN A VARIETY OF SEXUAL ACTS. EACH ACT CARRIES A DIFFERENT RISK FOR THE TRANSMISSION OF SEXUALLY TRANSMITTED DISEASES. HAVE YOU EVER HAD UNPROTECTED SEX, INCLUDING ORAL OR ANAL SEX, WITH THESE MEN?}

The physician should explain why such personal details need to be asked. Here, the physician continues to focus on unprotected heterosexual acts, ignoring much of Kate's sexual life. Questions should be more open-ended to cover the diverse range of sexual behavior, with the use of examples when required: "People participate in a variety of sexual acts with their partners. What acts have you participated in with your partners? Have you ever had digital-vaginal, oral-anal, or oralvaginal sex or used sex toys, for example? What sorts of protective barriers did you use?"

In this case, Kate's reply is useful: "When 


\section{Steps to creating a nonhomophobic environment \\ Place a "Lesbian, Gay, Bisexual, or Transgender-Safe Place" sticker on the clinic door \\ Place posters, pamphlets, and other reading material in the waiting area and examination rooms that are oriented to lesbian, gay, bisexual, and transgender people \\ Discuss and respect issues of confidentiality Use gender-neutral terms such as "partner" or "significant other" \\ Be aware of your own prejudices and biases and how they may affect your conversation \\ Know the distinction between sexual orientation and sexual behavior. Sexual behavior, not sexual orientation, confers risk of sexually transmitted diseases \\ Reassure lesbian, gay, bisexual, and transgender patients that they are normal \\ Be aware of local and national resources for these patients \\ Do not assume that all patients, friends, family, and colleagues are heterosexual \\ Do not refer patients to colleagues and/or services known to be homophobic or unsupportive \\ Do not try to guess who is gay, lesbian, bisexual, or transgender \\ Do not try to persuade a patient to choose a sexual orientation}

I was with each of the 2 men, we had vaginal intercourse and used condoms. With my first ex-girlfriend, we shared a dildo. We tried oral-anal sex once and fisting this other time. But with my other ex and my current girlfriend, it has been strictly manual-vaginal stimulation and oral-vaginal sex. We've always used gloves and dental dams when we've been together, though."

Whereas this may require further questioning regarding specific acts and the protection used with each act, it is more thorough than the initial inquiry. It opens the door for educating the patient about the risks associated with each act and how to prevent sexually transmitted diseases. Patients may need reassurance that sexual experimentation is normal and that they will not be judged on their sexual activities.

During the interview, Kate is distressed and exasperated as the physician continues the heterosexist line of questioning. Finally, the physician notices her discomfort and asks her what's wrong. She angrily replies that she is a lesbian, is currently in a relationship with a woman, and finds the questions insensitive and inappropriate. (Note that this is highly unlikely in reality. Patients are more likely to maintain their silence and never return to the health clinic.)

\section{APOLOGIZE. HOW LONG HAVE YOU BEEN A LESBIAN? WHEN DID YOU DECIDE YOU WERE A LESBIAN?}

These are inappropriate questions. Just as the following questions sound ridiculous to ask of heterosexuals, they can be offensive to sexual minorities: "When did you realize you were heterosexual? How did people react when you told them you were heterosexual?"

\section{Questions should be more}

\section{open-ended to cover the}

\section{diverse range of sexual}

\section{behavior}

\section{ARE YOU COMFORTABLE WITH YOUR OWN SEXUALITY? HAVE YOU SOUGHT THERAPY FOR THIS?}

Although it is important to discuss how comfortable Kate is with her own sexuality, being a lesbian does not automatically make her a candidate for therapy. By asking if she needs therapy, the physician is implying that being lesbian is a mental illness and that it requires a cure. Being homosexual is not an illness and, therefore, does not require treatment or a cure.

Patients need to be reassured when they are discussing their sexuality: "I realize that dealing with your own sexuality can be diffi-

\section{Unfortunately, the biases}

\section{and prejudices of society}

are not always left at the

\section{door to the examination}

\section{room}

cult. Many people struggle with this issue, whether they are heterosexual, gay, lesbian, bisexual, or transgender. How do you feel about your own sexuality?"

In addition, the physician should acknowledge societal restraints on sexual expression, but emphasize that most physicians do not subscribe to those viewpoints: "Many people mistakenly believe homosexuality is wrong. Have you experienced any such difficulties or discrimination?"

\section{CONCLUSIONS}

The above suggestions present an alternative approach to the difficult task of discussing sex and sexuality with patients. By phrasing questions in a gender-neutral, nonjudgmental manner, a thorough sexual history can be obtained while improving patient-physician rapport. Other methods of creating a nonhomophobic environment are outlined in the accompanying box.

References

1 Kinsey AC, Pomeroy W, Martin C. Sexual Behavior in the Human Male. Philadelphia: WB Saunders; 1948.

2 Kinsey AC, Pomeroy W, Martin CE, et al. Sexual

Behavior in the Human Female. Philadelphia: WB

Saunders; 1953.

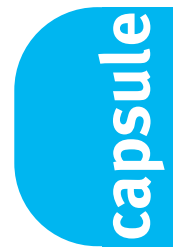

Bottled water contains more bugs Officials in Cleveland, Ohio, keep a close eye on the content and purity of tap water. They care much less about the content and purity of bottled water, even though Americans drink 4 billion gallons of it each year. Perhaps that is why some of the bottled samples in a comparative study contained 10 times more bacteria than tap water (Arch Fam Med 2000; 9:246-250). The authors note that water companies have to report water quality to the public or face prosecution. Manufacturers of bottled water have no such obligation. 